INTERNATIONAL DESIGN CONFERENCE - DESIGN 2018

https://doi.org/10.21278/idc.2018.0398

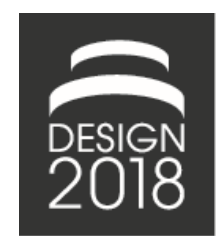

\title{
ASSESSING THE VALUE OF RADICAL TECHNOLOGY ALTERNATIVES AT SYSTEM LEVEL
}

\author{
M. Panarotto, O. Isaksson and L. Asp
}

\begin{abstract}
This study investigates the challenge to assess value when alternative technologies - of radical nature are integrated on complex products. The study highlights three main challenges: 1) value depends on how the overall product platform is impacted over time 2 ) value depends on combination effects between technologies and 3) value depends on how the technology balances internal and external stakeholders needs simultaneously. The paper describes how these challenges can be tackled by novel modelling methods, illustrated with an example related to structural batteries.
\end{abstract}

Keywords: value driven design, product platform, early design phase

\section{Introduction}

Few complex and advanced products (such as aircraft, automobiles and satellites) are developed from scratch. One common form of product evolution is by integration - or infusion (Suh et al., 2010) - of new technologies into existing product platforms and architectures. Despite significant technology assessment efforts, product development projects frequently struggle in integrating new technologies (Henderson and Clark, 1990). This is because new technologies are typically developed as prototypes 'in the laboratory' where they are gradually matured. When these technologies are proposed for integration into the product architecture, engineers and manager need to assess the impact - or 'value of such integration onto the overall system (Tahan and Ben-Asher, 2008). Such assessment efforts often treat the value of technologies in isolation (Smaling and de Weck, 2007), i.e. compare how a new technology improves the performances of an existing technology. Great advantages are missed for the integration of technologies which may present a lower level of performance than an existing technology, but may provide many benefits when looking at the overall system. An example can be offered by the assessment of technology alternatives for energy storage in electric vehicles (e.g., batteries). A key performance parameter for batteries is the energy density (i.e. how much energy can be stored, expressed in $\mathrm{Wh} / \mathrm{kg}$ ). For many years, improving energy density has been the main focus of the battery industry, developing new technologies to increase storage performance (such as the lithium-ion cells used in Tesla vehicles). Yet, such batteries come with the downside of increasing the total weight of the vehicle, which still represents the main obstacle for mainstream adoption of electric vehicles. A promising alternative technology for energy storage is offered by structural batteries. Compared to lithium-ion cells, structural batteries are composite materials which possess a lower energy density (Asp and Greenhalgh, 2014), but provide the possibility to replace structural components of a vehicle (e.g., steel body panels) with materials that can store energy like a battery. Such materials enable to take away the centralized battery and dramatically reduce weight at system level (Asp et al., 2015). Hence, the total energy required to operate the vehicle is lower, potentially contributing to the mainstream adoption of electric vehicles. 
Successful integration is thus a matter of 'foreseeing' the value of a technology on overall system behaviour. Yet, when technologies are proposed for integration into product platforms many design decisions on the overall system have already been made (Suh et al., 2010). Informed decisions have to be made early (already on a concept level), where designs can be changed spending little time and effort. The downside of making decisions early is that the full set of information may not be available at these stages (Ullman, 2002). This paper addresses this challenge, focusing on the situation when benefits can be related to the combination of technologies in new system arrangements, called architectures. This paper hence explores the following research question: "How can system value be assessed - when radically integrating technologies into the architecture?

\section{Research context and methodology}

This paper reports from initial research activities conducted in a EU-funded space development project (CHEOPS, 2018). The aim of these activities is to support industrial partners on value assessment, technology comparison and trade-off analysis with novel methodological approaches. Nine manufacturers are involved in the development of three different Electric Propulsion Systems (EPS) for satellites, which are intended to serve different application fields or orbits. The partners involved in the project are working at system and sub-system levels (such as flow management and power processing). The project is characterized by an ambitious cost reduction target for all the different EPS concepts. At the same time the project intends to provide performance enhancements, and in several cases also new functionalities. The comparison with existing concepts is therefore not straightforward, since the project is not only a cost reduction initiative.

The results provided in this paper emerge from the combination of a literature review with the preliminary empirical findings derived in the project. Empirical data has been collected during interviews and workshops with participants from the industrial partners. The data has been collected using field notes and reflections, which was then distributed to the participants for verification and their opportunity to change statements. The findings from these interviews have been integrated with observations gathered in previous projects within the aerospace and automotive industry.

The following chapters discuss the challenges identified in the literature review and the empirical study, The integrated analysis of this material led to the definition of a value assessment strategy (with associated methods) to be adopted as decision-support in the project. This strategy is illustrated according to an example related to structural batteries (Asp and Greenhalgh, 2014), due to the difficulty to disclose data in such an initial stage of the space development project.

\section{Value of technology integration: From assessment in isolation to assessment at system level}

Traditional approaches to value analysis - such as value engineering (VE) (Miles, 1972) - demonstrated powerful methods in product development for over 50 years (Palmer, 1992), yet become constrained when alternative technologies - of radical nature - are integrated on system architectures. In VE, alternatives are compared in isolation (Smaling and de Weck, 2007) in terms on how they contribute to deliver the required functional performance, compared to the cost for achieving such level of performance.

Literature points to two main challenges when assessing the value of radical technology alternatives into existing product platforms:

1. Value is realised through combined effects between technologies

2. Value depends on the context in which internal and external stakeholders operate the system

These two challenges constrain traditional approaches to value analysis, based on the comparison of technologies in isolation. The following sections develop further these challenges, introducing emerging methodological trends in these contexts.

\subsection{Value of combined effects between technologies: Challenges and approaches}

Research in Systems Engineering (e.g., Smaling and de Weck, 2007; Suh et al., 2010; ElMaraghy et al., 2012) emphasizes how the value impact of a technology is depending on combination effects between 
a mix of different types of technologies. For example, structural batteries can offer limited performance as a battery, and not be the optimal structural solution in isolation, but when assessing total system functional performance a structural battery solution may outperform system designs based on technologies working in isolation (Asp and Greenhalgh, 2014). Examples of functionality that can be integrated in one solution in this case is not only energy storage and structural integrity, but also energy transport, integrated sensors and wiring - further reducing the total weight of vehicles (Figure 1).

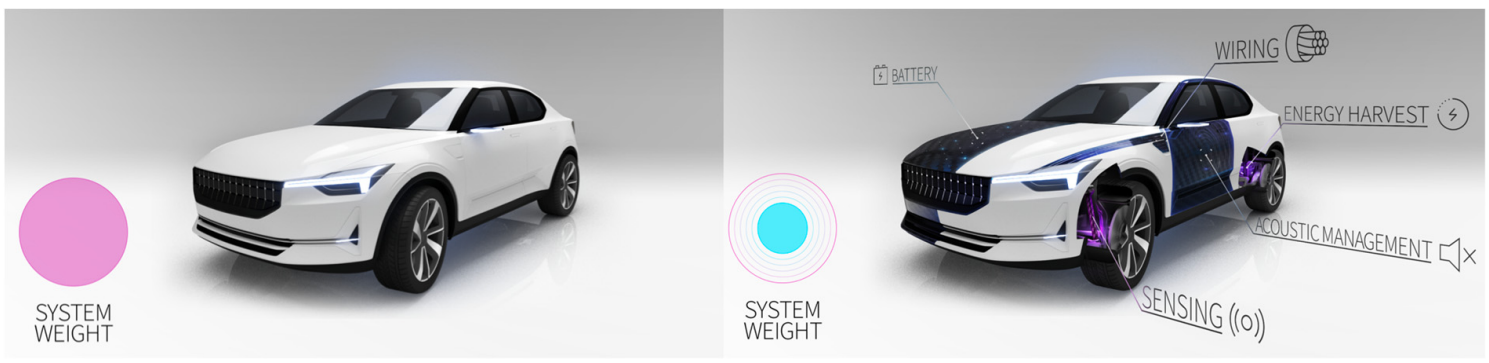

Figure 1. Integrating structural composite materials into different technologies (battery, sensors, wiring) can dramatically decrease the total weight of a vehicle

Evaluating such combinatorial effects is becoming more important nowadays due to the current evolution of the technological landscape . which is providing new ground-breaking technologies (such as additive manufacturing or electro mobility) that have matured and enable to improve functionality to a new level. To enable the assessment of technology combinations, literature stresses the importance of firstly representing such interdependencies (Suh et al., 2010), since alternative concepts can be defined on the basis that:

- Alternative technologies fulfil the same functional requirement

- Alternative solutions can be formulated as combination of technologies

- A mix of different types of technologies

- Several functions can be integrated into one shared component, but also the opposite, where a function is distributed over different components.

Modelling approaches that allow such representations emerge from axiomatic design principles (Suh, 1990) and function-means trees (Andreasen, 1980; Hubka and Eder, 1987; Buur, 1990). For example, Enhanced Function-Means trees (EF-M) (Schachinger and Johannesson, 2000; Wahl and Johannesson, 2010) are graphical representations that allow to model Functional Requirements (FRs) and Design Solutions (DSs) as objects. The EF-M modelling approach provides means for describing the design spaces necessary for exploring several concepts in parallel. By assigning several alternative design solutions for one functional requirement, several conceptual solutions are modelled simultaneously (Schachinger and Johannesson, 2000). If applied to various levels of the EF-M tree, combinations of design solutions can be described, forming a wide set of concepts or architectural options (Levandowski et al., 2014). Compared to other representations based on function-means trees, the EF-M approach introduces other object types - Constraints $(C)$ - which are conditions that in any way constrain the available solution space. i.e. what solutions that can be allowed. The EF-M method also allows to link the different objects according to different relations, and allows to represent the interaction between solutions, depending on the type of interaction between the elements (e.g., spatial, energy, information, material) (James et al., 2011).

\subsection{Value dependence on the stakeholders' context: Challenges and approaches}

A product can perform according to a specification, yet the value come from how well it performs in the stakeholders' context, which is subjects to variations (Grönroos, 2006). Literature (e.g., Isaksson et al., 2013) stress the importance to make more explicit such variations early in the development process, clarifying the intent of the forthcoming value assessment studies before validated requirements are available to the partners. Furthermore, literature emphasizes the importance to balance and trade internal and external needs simultaneously during the development process. External stakeholders typically have 
expectations and needs on the functionality and performance of the product once it is in use (e.g. an airline who expect the aircraft to be operable on a specific route with a specific payload). Internal stakeholders (such as company owners and top managers) have other expectations, typically related to cost and risk of development and production (e.g., capability to be flexible in production volume). Often, internal needs are considered in later phases of the project, which leads to technical solutions that are costlier for the manufacturer, as well as prone to schedule delays (Collopy, 1997).

For these reasons, a framework for Value Driven Design was developed (Isaksson et al., 2013), proposing the use of a common platform - defined as Value Creation Strategies (VCS) - as a means to enable the articulation of prioritized high level stakeholder needs into the design and development process. VCSs are intended to established a common framework in which the stakeholders can communicate the evolution (or change) of importance of stakeholder needs. For example, VCSs can be defined as: 'This study will explore the boundaries for maximising performance to weight ratio', or 'this study will minimise the effort and risk to integrate new technologies into an existing system'.

Literature in engineering decision making emphasizes the need to 'objectify' value. Make value quantifiable (Collopy and Hollingsworth, 2011) provides a practical and objective metric to solve the multiple design trade-offs that engineers encounter in the development process, and to make it easier to communicate value at decision-gates . Studies in Value Driven Design (Collopy and Hollingsworth, 2011) within aerospace (Price et al., 2012) space (Brown et al., 2009) and construction equipment (Panarotto, 2015; Panarotto et al., 2017) stress the convenience of a monetary system value function as a manner to engage all the stakeholders in a practical, convenient measure targeting the whole system lifecycle. These studies emphasize how many industry structures are complex, with competing customers, manufacturers, and lower-tier suppliers. This increases the difficulty of defining a monetary definition for value. To simplify the effects of competition, VDD adopts a Surplus Value theory (Collopy, 1997; Cheung et al., 2012) to identify such measure for value. The Surplus Value Theory provides a simplified equation that is a subset of Net Present Value (NPV) (Vanhoucke et al., 2001) based on several assumptions. In accordance with the Surplus Value Theory, the model optimizes the combined profit of the customer, the manufacturer and eventual suppliers. The theory hence strives for optimization of the combined profit of an imaginary corporation that performs all three roles. Surplus Value is simpler to compute because it is not affected by the actions of competing manufacturers (Price et al., 2012). The computation of a Surplus Value model requires however results from simulation tools to provide information on how the alternatives impact on Surplus Value. For example, physics-based simulations (such as Finite Element Analyses and Computation Fluid Dynamics), process-based such as discrete event simulation (Browning and Eppinger, 2002) or using the information contained in some updates of the Design Structure Matrix (DSM) such as the Change Propagation method (Clarkson et al., 2004; Raudberget et al., 2015).

\section{A strategy for value assessment of radical technologies at system level}

Three main aspects are highlighted by the practitioners participating in the project:

- The ability to represent the functionality of the system is crucial to compare radical technology alternatives.

- The value of a technology is dependent on the use context, hence, how the stakeholders use the system.

- There is a need for a model able to aggregate the value contribution of a technology on the system behaviour and the stakeholder context.

Enhancing such capabilities is therefore crucial to trade the value of a technology insertion against other dimensions. One typical trade-off is related to the value of a technology against its cost, however other dimensions related to many "ilities" (Rhodes et al., 2009) (such as the ability to maintain the product functionality in the presence of change) are crucial to be considered as well.

The consideration of these aspects leads to the definition of a strategy - or a framework - for value assessment. One aspect to be considered here is the need for a flexible and scalable approach that accommodates changes in requirements, functionalities and technology alternatives (which are prerequisites that differ between development projects). The defined strategy is depicted in Figure 2. 


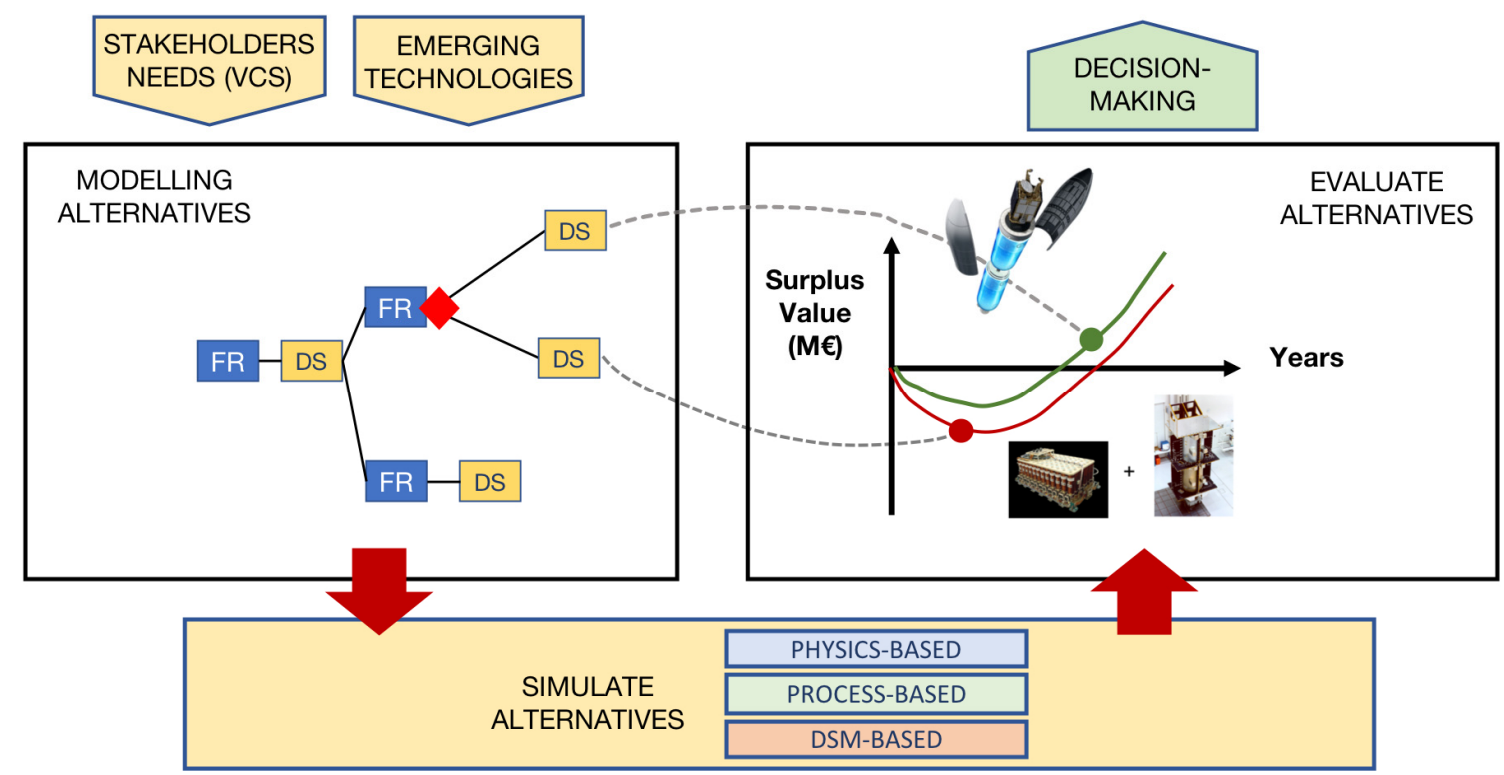

Figure 2. Defined strategy for value assessment of radical technology alternatives

The objective of this modelling approach is to enable decision-makers to visualize the impact of technology alternatives on the Surplus Value model. This strategy takes as input the stakeholders needs and expectations about the system (captured as VCSs with rank weights) and technology alternatives proposed for integration in the architecture. Architectural alternatives are modelled using EF-M trees, and are subsequently simulated in order to populate the Surplus Value model.

Due to the difficulty to disclose data in such an initial stage of the space development project, the approach is illustrated according to an example related to structural power composite materials (Asp and Greenhalgh, 2014).

\subsection{Preparing the input for value assessments}

The example deals with an all-electric aircraft. The reference aircraft is the E-Fan 1.0 (referred to as EFan in the following) developed by the Airbus Group, since was designed from the beginning on as an all-electric aircraft and was mainly built with composites. The E-Fan (Table 1) is intended to be used as a general aviation trainer aircraft. It is a two-seater aircraft in fixed-wing configuration having two retractable landing gears under the fuselage and two smaller gears located under the wings. Two electric motors power two eight-blade ducted fans, which are mounted over the wings to reduce noise. The conventional battery packs are placed in the wings, close to the root. Expected growth in air traffic and an increasing environmental awareness drive the need for new technologies in aerospace. To attain emission and noise targets, all-electric aircraft are a promising technology, but relatively low specific energies of current batteries make them very heavy. By combining energy-storage and load-bearing capabilities in a multifunctional material, structural power technology addresses this problem, promising substantial savings in weight. The input data for this example are taken from (Scholz, 2017), who presented a feasibility study of structural power technology for this type aircraft.

The first step in the proposed value assessment strategy is to capture and rank-weight the stakeholders needs and expectations. In this phase, Value Creation Strategies (VCSs) are prepared at the 'aircraft level', including external as well as internal stakeholders. Different weights are given for the different strategies under investigation. The weights range from 5 (being the most important need in one specific VCS) to 1 being the least important. Such weights are set after the collective and iterative effort among the partners participating in the development project. For example, in a single design (one-off) aircraft used for high performance applications (e.g., private jets), needs related to range and energy efficiency are considered more important than the cost for repair. 
Table 1. Value Creation Strategies for electric aircraft

\begin{tabular}{|c|c|c|c|c|}
\hline \multicolumn{3}{|c|}{ AIRCRAFT LEVEL } \\
\hline $\begin{array}{c}\text { Type of } \\
\text { stakeholder }\end{array}$ & Stakeholder need & $\begin{array}{c}\text { VCS1: one-off } \\
\text { design, } \\
\text { performance } \\
\text { optimized }\end{array}$ & $\begin{array}{c}\text { VCS2: one-off } \\
\text { design, repair cost } \\
\text { optimized }\end{array}$ & $\begin{array}{c}\text { VCS3: } \\
\text { platform } \\
\text { aircraft design }\end{array}$ \\
\hline External & Increase range & 5 & 3 & 3 \\
\hline External & $\begin{array}{c}\text { More efficient use of } \\
\text { energies }\end{array}$ & 4 & 4 & 3 \\
\hline External & Reduce costs for repair & 2 & 5 & 1 \\
\hline Internal & $\begin{array}{c}\text { Increase commonality } \\
\text { in production }\end{array}$ & 1 & 1 & 4 \\
\hline Internal & $\begin{array}{c}\text { Design process } \\
\text { efficiency }\end{array}$ & 1 & 1 & \\
\hline
\end{tabular}

Another VCS for a single design may instead be related to the need of investigating designs for low repair costs. In fact, for some commercial application (e.g., low-cost airlines) performances can be considered less valuable than repair costs (although still important). Also, the manufacturer would wish to apply a platform design strategy in order to produce many generations and variants of aircraft from a platform (as opposed to the one-off design strategy). An internal stakeholder need - commonality in production - is stressed in this VCS, set more important performances and repair costs. Another important stakeholder need in platform design is 'design process efficiency': it expresses the complexity of an architecture driving costly design iterations in the presence of change. The design team is set out to search for such solutions that are strong in these values. This preparation phase allows to define and share between the partners ranges of assessment studies - before validated requirements become available.

\subsection{Modelling technological alternatives}

Once the VCSs are expressed, the function modelling mechanism is called to identify the functionality needed, and to capture technology alternatives. Functional modelling is used to facilitate the decomposition of needs into functional requirements $(F R s)$. After FRs are specified, Design Solutions $(D S s)$ can be identified as alternative means to solve functionality. In this activity an Enhanced-Function Means (EF-M) approach can be used, as it allows to capture the interactions between DSs, with an $i w$ ('interacts with') link. These interactions can be of space, mechanical, fluid, information or energy nature (James et al., 2011). The benefit of adopting EF-M trees is that these interactions can be captured, and exported as DSMs to evaluate 'ilities' related to the complexity of the architecture, such as flexibility, integration ability or design process efficiency (Raudberget et al., 2015).

In Figure 3, a small part of an EF-M structure for the electric aircraft is shown. It focuses on highlighting how alternative solutions can be formulated for the same functional requirement. The function 'store energy source' can be fulfilled by two solutions, connected in Figure 3 with an isb ("is solved by") link. One alternative (Option B) is a set of multiple battery cells, the other one (Option A) is a structural battery composite material. This DS is formulated as 'use carbon fibres as anode and cathode' expressing the solution of using layers of polymer-infused carbon fibres in a composite material as anode and cathode (Asp and Greenhalgh, 2014). Such design solution is integrated into the composite wing structure, and the EF-M model captures this relationship with an $i w$ ('interacts with') relation. These types of relations are important to be able to assess combination effects between solutions. For example, the battery pack (Option B) is placed inside the aircraft, and a common solution is to make a 
hollow wing structure to place the batteries. This solution interacts with the wing profile (through a spatial connection, captured with an $i w$ link). With structural batteries, there is no need for placing the batteries (hence there is no $i w$ link between the structural battery and the wing). Hence, there is no need for a hollow wing structure. This has profound impact on aircraft design, as the wing profile can be made be shorter, and slender, reducing drag and weight even further (Scholz, 2017).

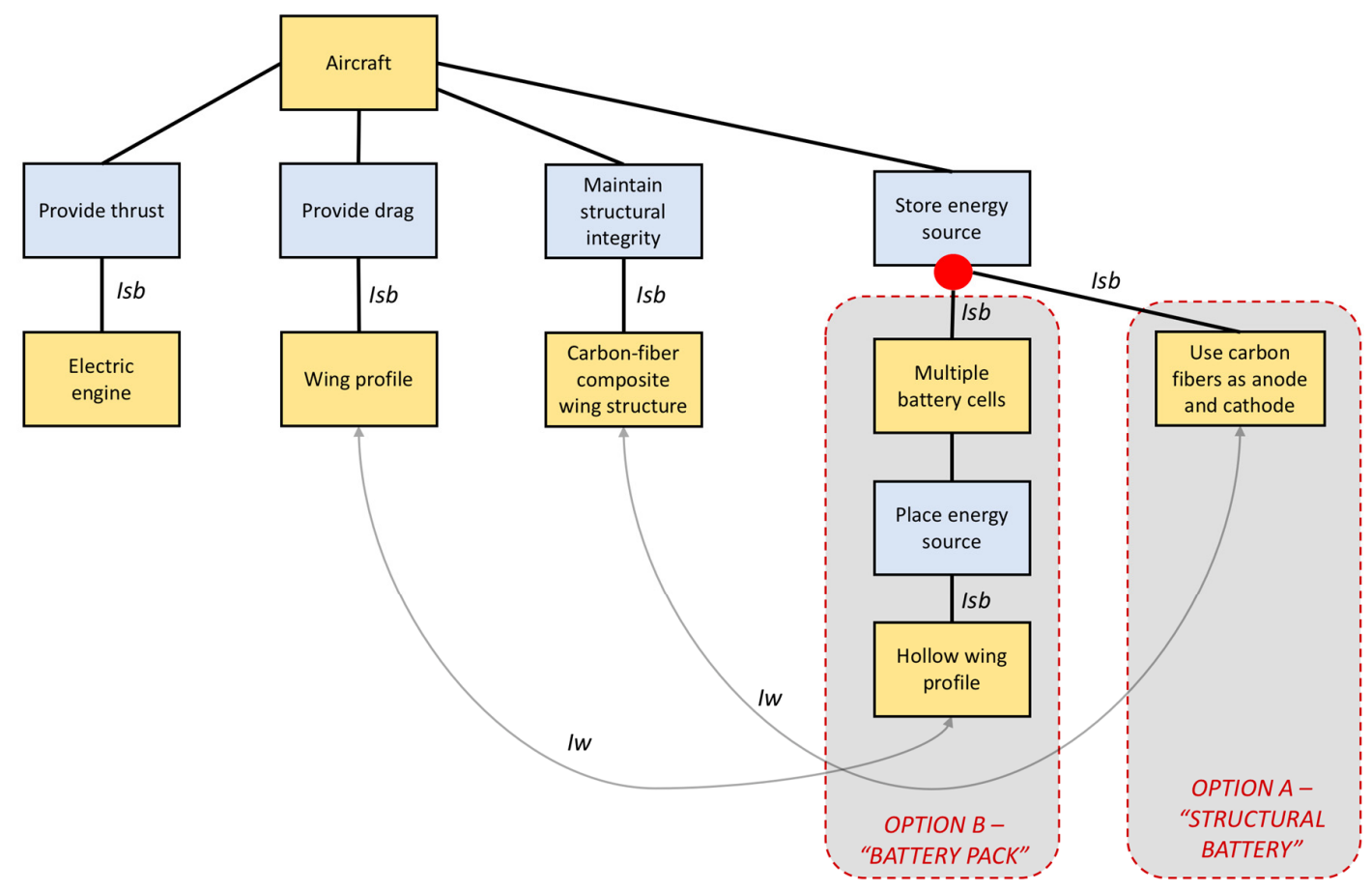

Figure 3. Simplified EF-M tree for the case of structural batteries

\subsection{Evaluate alternatives through the Surplus Value model}

After the alternatives have been generated and modelled with EF-M trees, the impact of alternatives on system behaviour (and the stakeholder context set by the VCSs) is visualized on the Surplus Value model, to engage decision-makers in a practical, convenient measure - targeting the whole system lifecycle. Figure 4 provides an example of the Surplus Value assessment of three different options for the aircraft presenting different technological alternatives. The Surplus Value of the aircraft program is computed in million €uro along a 20 years lifetime, taking into account development and operation of aircraft sold in the market. The figures are only meant to be demonstrative for visualization purposes.

One instance for such assessment is represented by the option of storing energy source with battery packs - Option B. In this example, option B is characterized by a longer pay-back, and hence a lower Surplus Value. This is mapping the higher energy costs required to operate a heavier aircraft. As opposed, structural composite materials (Option A) present higher Surplus Value, as they allow to remove a heavy $167 \mathrm{~kg}$ of battery pack (Scholz, 2017). Additionally, Option A allows to design shorter wings (since they do not have to be hollow anymore, to store the battery pack), further decreasing weight (and hence energy costs for the same range). With visualization, the impact of technology options can be assessed and tested according to the different Value Creation Strategies defined in the preparation phases. For example, Option $\mathrm{C}$ presents the study where structural batteries are used in the context of a platform strategy (VCS3) - in which many variants for the wing design are generated upon. It can be noted that such option features a longer lead time than Option A (one-off design with structural batteries). This is due to the lower design process efficiency. Changing composite structures to accommodate different wing designs means more feedback loops. This maps onto a longer and more costly design time, which increases the overall pay-back time for the option. A Surplus Value assessment allows to trade different aspects on the same figure of merit - targeting external and internal stakeholders 
needs simultaneously. For example, such visualization highlights the potential benefit of a structural battery option for external stakeholders (Option A), but it also stresses the challenges to meet internal stakeholders needs, due to the scalability of composite structures in the case of a platform design were many variants are generated upon.

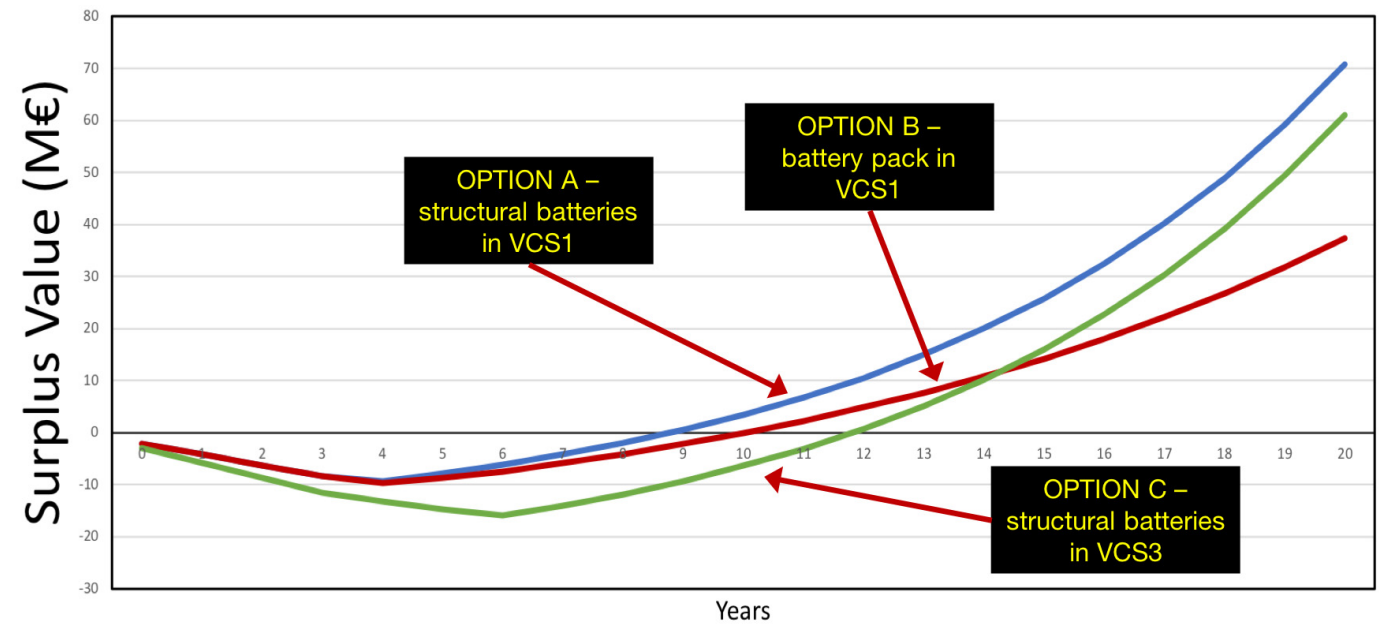

Figure 4. Surplus Value curves for three different architectural options

\section{Conclusions}

Value of technologies is realized on system level, yet when alternative technologies - of radical nature - are integrated on system level, the design decisions are already made. This is a challenge for designers, and the empirical study highlighted:

- The ability to represent the functionality of the system is crucial to compare radical technology alternatives.

- The value of a technology is dependent on the use context, hence, how the stakeholders use the system.

- There is a need for a model able to aggregate the value contribution of a technology on the system behaviour and the stakeholder context.

Preliminary findings indicate that the combined use of function modelling, Value Creation Strategies and Surplus Value analysis are key components for providing a powerful design support. Future work will focus on applying and validate the use of these combined supports into the current space project, assessing different alternatives for electric satellite propulsion.

\section{Acknowledgment}

The research leading to these results has received funding from the European Union's Horizon 2020 research and innovation programme (H2020/2014-2020) under grant agreement No 730135 (https://www.cheops-h2020.eu/).

\section{References}

Andreasen, M.M. (1980), Syntesemetoder på systemgrundlag: bidrag til en konstruktionsteori, $\mathrm{PhD}$ thesis, Lund Technical University, Lund, Sweden.

Asp, L.E. and Greenhalgh, E.S. (2014), "Structural power composites", Composites Science and Technology, Vol. 101, pp. 41-61. https://doi.org/10.1016/j.compscitech.2014.06.020

Asp, L.E., Leijonmarck, S., Carlson, T. and Lindbergh, G. (2015), "Realisation of structural battery composite materials", 20th International Conference on Composite Materials (Proceedings), pp. 1121-1122.

Brown, O.C., Eremenko, P. and Collopy, P.D. (2009), "Value-centric design methodologies for fractionated spacecraft: Progress summary from phase 1 of the DARPA System F6 program", AIAA SPACE 2009 Conference \& Exposition, p. 2009. https://doi.org/10.2514/6.2009-6540 
CHEOPS (2018), Consortium for Hall Effect Orbital Propulsion System. [online] Available at: https://www.cheops-h2020.eu/ (accessed 19.03.2018).

Cheung, J., Scanlan, J., Wong, J., Forrester, J., Eres, H. et al. (2012), “Application of value-driven design to commercial aeroengine systems. Application of value-driven design to commercial aeroengine systems", Journal of Aircraft, Vol. 49 No. 3, pp. 688-702. https://doi.org/10.2514/1.C031319

Clarkson, P.J., Simons, C. and Eckert, C. (2004), "Predicting Change Propagation in Complex Design", Journal of Mechanical Design, Vol. 126 No. 5, pp. 788-797. https://doi.org/10.1115/1.1765117

Collopy, P.D. (1997), "Surplus value in propulsion system design optimization", 33rd Joint Propulsion Conference and Exhibit. https://doi.org/10.2514/6.1997-3159

Collopy, P.D. (1997), “A System for Values, Communication and Leadership in Product Design”, International Powered Lift, Conference Proceedings, SAE Publications, pp. 95-98.

Collopy, P.D. and Hollingsworth, P.M. (2011), "Value-Driven Design", Journal of Aircraft, Vol. 48 No. 3 , pp. 749-759. https://doi.org/10.2514/1.C000311

ElMaraghy, W., ElMaraghy, H., Tomiyama, T. and Monostori, L. (2012), “Complexity in engineering design and manufacturing”, CIRP Annals-Manufacturing Technology, Vol. 61 No. 2, pp. 793-814. https://doi.org/10.1016/j.cirp.2012.05.001

Grönroos, C. (2006), “Adopting a service logic for marketing”, Marketing theory, Vol. 6 No. 3, pp. 317-333. https://doi.org/10.1177/1470593106066794

Henderson, R.M. and Clark, K.B. (1990), "Architectural innovation: The reconfiguration of existing product technologies and the failure of established firms", Administrative science quarterly, Vol. 35 No. 1, pp. 9-30. https://doi.org/10.2307/2393549

Hubka, V. and Eder, W.E. (1987), Principles of Engineering Design, Heurista, Zurich.

Isaksson, O., Kossmann, M., Bertoni, M., Eres, H., Monceaux, A. et al. (2013), "Value-Driven Design-A methodology to Link Expectations to Technical Requirements in the Extended Enterprise", INCOSE International Symposium, Vol. 23, No. 1, pp. 803-819. https://doi.org/10.1002/j.2334-5837.2013.tb03055.x

James, D., Sinha, K. and de Weck, O. (2011), "Technology insertion in turbofan engine and assessment of architectural complexity", DSM 2011: Proceedings of the 13th International DSM Conference.

Levandowski, C., Raudberget, D.S. and Johannesson, H. (2014), "Set-Based Concurrent Engineering for Early Phases in Platform Development", The 21st ISPE International Conference on Concurrent Engineering CE2014, pp. 564-576.

Miles, L.D. (1972), Techniques of Value Analysis and Engineering, McGraw Hill, New York.

Palmer, A. (1992), An investigative study of value engineering in United states of America and its relationship to United Kingdom cost control procedures, PhD Thesis, Loughborough University of Technology.

Panarotto, M. (2015), A Model-Based Methodology for Value Assessment in Conceptual Design, PhD Thesis, Blekinge Institute of Technology, Karlskrona, Sweden.

Panarotto, M., Wall, J., Bertoni, M., Larsson, T. and Jonsson, P. (2017), "Value-driven simulation: Thinking together through simulation in early engineering design", 21st International Conference on Engineering Design (ICED), Vancouver, The Design Society.

Price, M., Soban, D., Mullan, C., Butterfield, J. and Murphy, A. (2012), "A novel method to enable trade-offs across the whole product life of an aircraft using value driven design", Journal of Aerospace Operations, Vol. 1 No. 4, pp. 359-375.

Raudberget, D., Levandowski, C., Isaksson, O., Kipouros, T., Johannesson, H. and Clarkson, J. (2015), "Modelling and assessing platform architectures in pre-embodiment phases through set-based evaluation and change propagation", Journal of Aerospace Operations, Vol. 3 No. 3, 4, pp. 203-221.

Rhodes, D.H., Ross, A.M. and Nightingale, D.J. (2009), “Architecting the system of systems enterprise: Enabling constructs and methods from the field of engineering systems", Systems Conference, 2009 3rd Annual IEEE, pp. 190-195.

Schachinger, P. and Johannesson, H.L. (2000), "Computer modelling of design specifications", Journal of Engineering Design, Vol. 11 No. 4, pp. 317-329. https://doi.org/10.1080/0954482001000935

Scholz, A.E. (2017), Feasibility Analysis and Comparative Assessment of Structural Power Technology in AllElectric Composite Aircraft, Master Thesis, Imperial College London.

Smaling, R. and de Weck, O.D. (2007), "Assessing risks and opportunities of technology infusion in system design”, Systems Engineering, Vol. 10 No. 1, pp. 1-25. https://doi.org/10.1002/sys.20061

Suh, E.S., Furst, M.R., Mihalyov, K.J. and Weck, O.D. (2010), "Technology infusion for complex systems: A framework and case study”, Systems Engineering, Vol. 13 No. 2, pp. 186-203.

Suh, N.P. (1990), The Principles of Design, Oxford University Press, New York, USA.

Tahan, M. and Ben-Asher, J.Z. (2008), "Modeling and optimization of integration processes using dynamic programming", Systems Engineering, Vol. 11 No. 2, pp. 165-185. https://doi.org/10.1002/sys.20092

Ullman, D.G. (2002), The Mechanical Design Process, McGraw-Hill. 
Vanhoucke, M., Demeulemeester, E. and Herroelen, W. (2001), "On maximizing the net present value of a project under renewable resource constraints", Management Science, Vol. 47 No. 8, pp. 1113-1121. https://doi.org/10.1287/mnsc.47.8.1113.10226

Wahl, A. and Johannesson, H. (2010), "Managing Design Change in Configurable Component Based Platforms", Proceedings of the 8th Biannual Conference NordDesign 2010, Gothenburg, Sweden, August 25 - 27, 2010.

Dr. Massimo Panarotto

Chalmers University of Technology, Industrial and Materials Science

Maskingränd 2, 41258 Göteborg, Sweden

Email: massimo.panarotto@chalmers.se 